\title{
Repeated and long-term treatment with physiological concentrations of resveratrol promotes NO production in vascular endothelial cells
}

\author{
Satoru Takahashi ${ }^{1,2 *}$ and Yukiko Nakashima ${ }^{2}$ \\ ${ }^{1}$ Department of Immunobiology, School of Pharmacy and Pharmaceutical Sciences, Mukogawa Women's University, \\ 11-68 Kyuban-cho, Koshien, Nishinomiya, Hyogo 663-8179, Japan \\ ${ }^{2}$ First Department of Biochemistry, School of Pharmaceutical Sciences, Kyushu University of Health and Welfare, \\ 1714-1 Yoshino, Nobeoka, Miyazaki 882-0072, Japan
}

(Received 22 December 2010 - Revised 16 May 2011 - Accepted 2 June 2011 - First published online 27 July 2011)

\section{Abstract}

In the present study, we examined the effect of repeated and long-term treatment with resveratrol on NO production in endothelial cells as a model of routine wine consumption. Repeated treatment with resveratrol for $5 \mathrm{~d}$ resulted in an increase in endothelial NO synthase (eNOS) protein content and NO production in human umbilical vein endothelial cell (HUVEC) in a concentration-dependent manner. A significant increase in functional eNOS protein content was observed with resveratrol, even at 50 nM. In contrast, eNOS phosphorylation was not stimulated and inducible NO synthase (iNOS) was not detected after resveratrol treatment. Both eNOS protein and mRNA expression were promoted by $50 \mathrm{~nm}$-resveratrol in a time-dependent manner. Increased eNOS mRNA expression in response to resveratrol was not decreased by an oestrogen receptor (ER) antagonist ICI182780, a PPAR $\alpha$ inhibitor MK886 or a sirtuin inhibitor Salermide. However, a combination of ICI182780 and MK886 significantly inhibited resveratrol-induced eNOS mRNA expression. Salermide had no effect even in the presence of ICI182780 or MK886. These results demonstrate that resveratrol within the physiological range increases eNOS mRNA and protein expression through ER and PPAR $\alpha$ activation, thereby promoting NO production in endothelial cells. eNOS induction might result from the accumulative effect of nanomolar concentrations of resveratrol. The present study results can account in part for the observation that cardiovascular benefits of red wine are experienced with routine consumption, but not with acute consumption.

Key words: Resveratrol: Endothelial cells: NO synthase: Gene expression

Epidemiological studies have demonstrated that dietary polyphenol intake including red wine consumption might improve endothelial function and reduce the risk of $\mathrm{CVD}^{(1-3)}$. Resveratrol (trans-3,5,4'-trihydroxystilbene) is a polyphenol abundantly found in grapes, and is a key compound implicated in cardiovascular benefits associated with red wine consumption ${ }^{(3,4)}$. Routine consumption of polyphenols is required for cardioprotection, suggesting that expression of specific genes in the vasculature is one of possible mechanisms of the beneficial effect of resveratrol.

$\mathrm{NO}$ in the vasculature is synthesised by endothelial NO synthase (eNOS) and is an important regulator of cardiovascular homoeostasis $^{(5)}$. NO prevents thrombogenic and atherogenic processes by exerting vasodilatory and anti-aggregatory effects. In animal models, the cardiovascular effects of resveratrol are mediated through $\mathrm{NO}^{(6-10)}$. Therefore, whether resveratrol increases eNOS expression and NO production in endothelial cells has been investigated. Wallerath et al. ${ }^{(11)}$ reported that exposure of cultured endothelial cells to resveratrol for 24-72 h up-regulates eNOS mRNA and protein expression, resulting in an increase in bioavailable NO. However, because the biological activities of resveratrol were observed between 10 and $100 \mu \mathrm{M}$, their experiments were not conducted under physiological conditions, in which concentrations were markedly higher than serum concentrations. Resveratrol concentrations in the blood were $20-50 \mathrm{~nm}$ after oral administration of $25 \mathrm{mg}$ resveratrol to healthy volunteers ${ }^{(12,13)}$. In addition, resveratrol at high concentrations $(>10 \mu \mathrm{M})$ decreased cell viability and induced both apoptosis and necrosis ${ }^{(14,15)}$. Nicholson et $a l^{(16)}$ investigated the effect of nanomolar concentrations of resveratrol on eNOS mRNA content in endothelial cells. Resveratrol treatment for $24 \mathrm{~h}$ increased

Abbreviations: eNOS, endothelial NO synthase; ER, oestrogen receptor; HUVEC, human umbilical vein endothelial cell; iNOS, inducible NO synthase; L-NAME, $N^{G}$-nitro-L-arginine methyl ester; MTT, 3-(4,5-dimethyl-2-thiazolyl)-2,5-diphenyl-2H-tetrazolium bromide; peNOS, phospho-eNOS 
eNOS mRNA content. However, this increase was modest, and neither eNOS protein nor NO production was determined. Thus, it remains unclear whether resveratrol at physiological concentrations promotes NO production through eNOS induction in endothelial cells.

In the present study, we examined the effect of repeated and long-term treatment with resveratrol on functional eNOS expression and NO production in endothelial cells as a model of routine wine consumption. Here we provide evidence that resveratrol at nanomolar concentrations increases the expression of functional eNOS protein.

\section{Materials and methods}

\section{Materials}

Unless otherwise indicated, the reagents used in the present study and their sources are as follows: resveratrol, 3-(4,5-dimethyl-2-thiazoyl)-2,5-diphenyl-2 $\mathrm{H}$-tetrazolium bromide (MTT), $N^{G}$-nitro-L-arginine methyl ester (L-NAME; Sigma-Aldrich Company, St Louis, MO, USA); human umbilical vein endothelial cell (HUVEC) and cell culture media and supplies (Sanko Junyaku, Tokyo, Japan); porcine type I collagen (Nitta Gelatin, Osaka, Japan); MK886, Salermide and protease inhibitor mixture set III (Calbiochem, La Jolla, CA, USA); anti-eNOS antibody, anti-iNOS antibody and anti$\beta$-actin antibody (BD Transduction Laboratories, Lexington, KY, USA); anti-peNOS antibody (phospho-Ser1177), secondary antibody linked to peroxidase, Phototope-HRP Western Blot Detection System and recombinant iNOS protein (Cell Signaling, Beverly, MA, USA); Immobilon-P membrane (Millipore, Bedford, MA, USA); ICI182780 (AstraZeneca Pharmaceuticals, London, UK); protein assay kit (Bio-Rad, Hercules, CA, USA); Sepasol-RNA (Nacalai Tesque, Kyoto, Japan). Resveratrol, Salermide, ICI182780 and MK886 were dissolved in dimethyl sulphoxide, with a final concentration of the solvent at $<0.5 \%$ in culture dishes. All other chemicals were of reagent grade.

\section{Cell culture}

HUVEC were maintained in endothelial cell basal growth-2 medium containing complete supplements (2\% charcoaltreated fetal bovine serum, epidermal growth factor, basic fibroblast growth factor, vascular endothelial growth factor, insulin-like growth factor-1, heparin, hydrocortisone, ascorbic acid and $\mathrm{GA}-1000$ ) at $37^{\circ} \mathrm{C}$ in $5 \% \mathrm{CO}_{2}$ and $95 \%$ air. Cells between passages five and ten were used in the experiments. All plates and dishes were coated with porcine type I collagen. HUVEC were seeded in $35-\mathrm{mm}$ dishes for immunoblotting and NO production and in $60-\mathrm{mm}$ dishes for quantitative RT-PCR. These cells were allowed to grow to approximately $50 \%$ confluence (day 0 ). Thereafter, the cells were incubated with resveratrol or vehicle for $1-5 \mathrm{~d}$ in endothelial cell basal growth- 2 medium containing $10 \%$ supplements and $1 \mathrm{mg} / \mathrm{ml}$ bovine serum albumin. The medium was replaced with new medium every $24 \mathrm{~h}$ according to the schedule shown in Fig. 1.

\section{Determination of NO synthase protein expression}

NO synthase protein was detected by immunoblotting and quantified as previously described ${ }^{(17)}$. HUVEC were lysed in $20 \mathrm{~mm}$-Tris- $\mathrm{HCl}$ (pH 7.5), $1 \mathrm{mm-EDTA,} 100 \mathrm{~mm}-\mathrm{NaCl}$, $10 \mathrm{~mm}$-sodium orthovanadate, $10 \mathrm{~mm}$-sodium fluoride, $10 \mathrm{~mm}$ $\beta$-glycerophosphate, $1 \%$ Triton X-100, 0.5\% sodium deoxycholate and protease inhibitor mixture. The lysates were placed on ice for $10 \mathrm{~min}$ and were then centrifuged at $10000 \mathrm{rpm}$ for $10 \mathrm{~min}$ at $4^{\circ} \mathrm{C}$. The supernatants were recovered, and protein concentration was determined using bovine serum albumin as a standard. The supernatants ( $25 \mu \mathrm{g}$ protein) were subjected to SDS-PAGE and were then blotted onto Immobilon-P membranes. The blots were incubated overnight with the primary antibody at $4^{\circ} \mathrm{C}$ and then probed with the peroxidaseconjugated secondary antibody. Immunoreactive proteins were visualised using an enhanced chemiluminescence kit. The intensity of each band was measured by densitometry

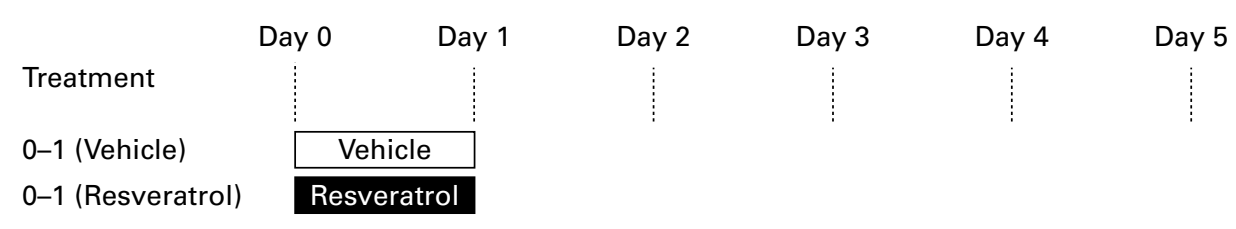

0-3 (Vehicle)

0-3 (Resveratrol) Resveratrol Resveratrol Resveratrol

$\uparrow$ Inhibitors $\uparrow$ Inhibitors $\uparrow$ Inhibitors

\begin{tabular}{l|c|c|c|c|c|}
\hline 0-5 (Vehicle) & Vehicle & Vehicle & Vehicle & Vehicle & Vehicle \\
\hline 0-5 (Resveratrol) & Resveratrol & Resveratrol & Resveratrol & Resveratrol & Resveratrol \\
2-5 & Vehicle & Vehicle & Resveratrol & Resveratrol & Resveratrol \\
\cline { 2 - 5 } $0-3-5$ & Resveratrol & Resveratrol & Resveratrol & Vehicle & Vehicle \\
\hline
\end{tabular}

Fig. 1. Schematic diagram of repeated treatment with resveratrol. Culture medium containing vehicle or resveratrol and/or inhibitors was replaced with new medium every $24 \mathrm{~h}$. 
and then normalised by calculating the ratio of NO synthase to $\beta$-actin. Thereafter, relative expression was determined in comparison with the control cells.

\section{Determination of endothelial NO synthase mRNA expression}

Total RNA were extracted from HUVEC using SepasolRNA followed by DNase I digestion. Complementary DNA were synthesised using SuperScript III SuperMix (Invitrogen, Carlsbad, CA, USA). eNOS mRNA content was assessed by real-time PCR on a Roche LightCycler (Roche Diagnostics KK, Tokyo, Japan), as described previously ${ }^{(18)}$. PCR primers used for eNOS and glyceraldehyde 3-phosphate dehydrogenase were $5^{\prime}$-CACATGTTTGTCTGCGG-3' and 5'-GAGGGGCCTTCCAGATTAAG- $3^{\prime}$, and $5^{\prime}$-ATGGCACCGTCAAGGCTGAGAAC- $3^{\prime}$ and $5^{\prime}$-GTTGCTGTACCAAATTCGTTGTC- $3^{\prime}$, respectively. eNOS mRNA expression was normalised to glyceraldehyde 3-phosphate dehydrogenase mRNA expression and then relative eNOS mRNA expression was determined in comparison with the control cells.

\section{Determination of NO production}

NO production was determined as generation of nitrite ${ }^{(14)}$. HUVEC were incubated in PBS containing $10 \mathrm{mm-HEPES-}$ $\mathrm{NaOH}(\mathrm{pH} 7 \cdot 4), 0 \cdot 1 \mathrm{~mm}-\mathrm{ATP}$ and $1 \mathrm{mg} / \mathrm{ml}$ bovine serum albumin for $30 \mathrm{~min}$ and then the medium was sampled. In experiments on eNOS inhibition $5 \mathrm{~mm}$-L-NAME was added. NO was determined as nitrite by colorimetry following the Griess reaction. NO released into the medium was converted to nitrate and nitrite when left overnight at $4^{\circ} \mathrm{C}$, and then nitrate was completely oxidised by nitrate reductase to nitrite. The amount of nitrite was measured using a NOx analyser (ENO-200, EICOM, Kyoto, Japan).

\section{Determination of cell viability}

Cell viability was determined by mitochondrial function assay, as described previously ${ }^{(14)}$. Mitochondrial function was assessed by the colorimetric method using MTT. After treating with resveratrol for $5 \mathrm{~d}$ the cells were incubated in the culture medium containing $1 \mathrm{mg} / \mathrm{ml}$ MTT for $2 \mathrm{~h}$ at $37^{\circ} \mathrm{C}$, the formed formazan was extracted with isopropanol containing $40 \mathrm{~mm}-$ $\mathrm{HCl}$. The absorbance at $595 \mathrm{~nm}$ in the extract was measured.

\section{Statistical analysis}

Data are presented as means with their standard errors. Statistical differences in the concentration-response study were evaluated by Dunnett's multiple comparison test. Student's $t$ test was used to compare the two groups. A $P$ value of $<0.05$ was regarded as significant.

\section{Results}

In the present study, we examined whether resveratrol at physiological concentrations enhances eNOS protein expression in endothelial cells. Repeated treatment with resveratrol for $5 \mathrm{~d}$ resulted in an increase in eNOS protein content in HUVEC in a concentration-dependent manner (Fig. 2). Resveratrol-induced eNOS protein expression started increasing from $10 \mathrm{~nm}$ and significantly increased at 50 and $200 \mathrm{~nm}(P<0 \cdot 01)$. This expression was $2 \cdot 5$-fold at $50 \mathrm{~nm}$ and $3 \cdot 1$-fold at $200 \mathrm{~nm}$ compared with the control cells. In contrast,
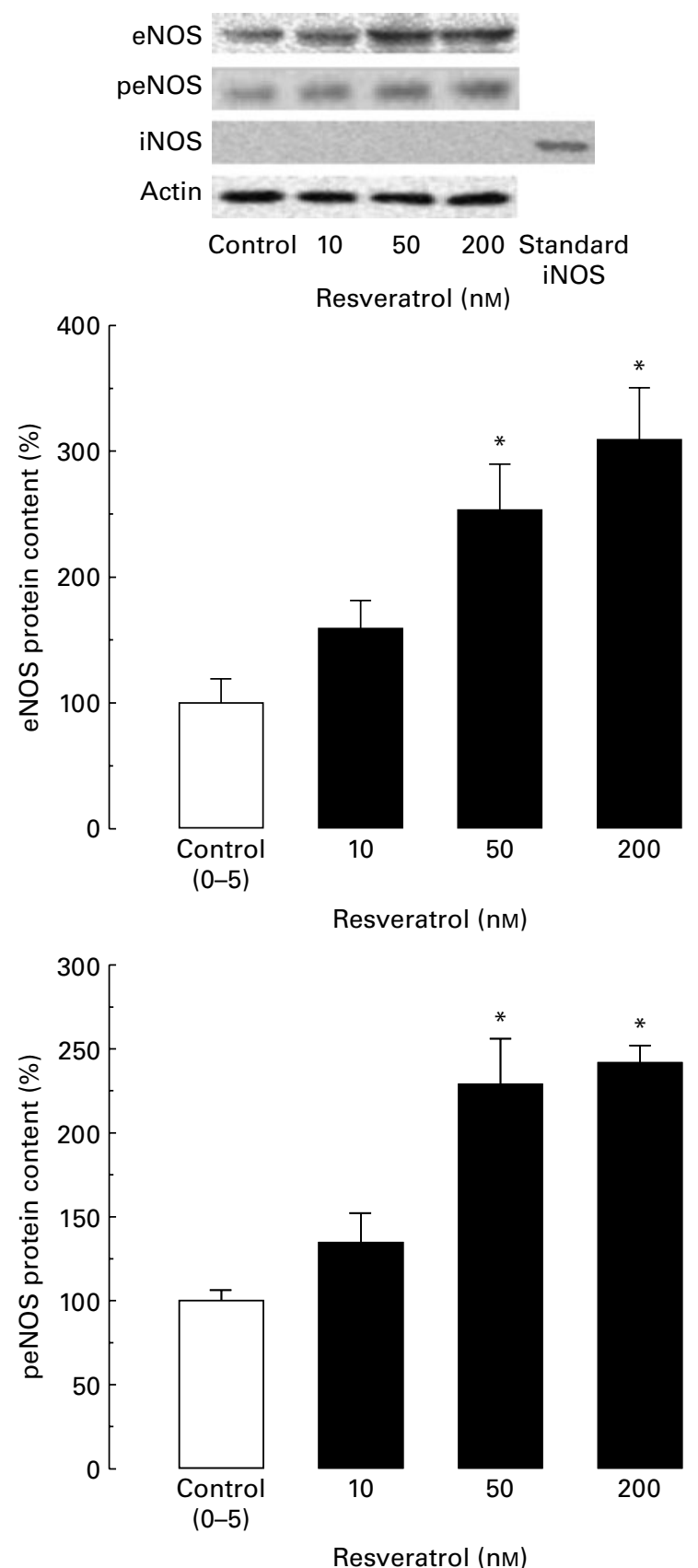

Fig. 2. Concentration-dependent effect of resveratrol on endothelial NO synthase (eNOS) protein expression in human umbilical vein endothelial cell (HUVEC). HUVEC were repeatedly treated with vehicle or 10-200 nM-resveratrol for $5 \mathrm{~d}$ : total and phospho-eNOS (peNOS) protein contents were then examined by immunoblotting. The ratio of total or peNOS to $\beta$-actin was determined by densitometry and expressed as a percentage of the control (vehicle) cells. Values are means, with their standard errors represented by vertical bars $(n 8)$. * Mean values were significantly different from those of control $(P<0 \cdot 01)$. iNOS, inducible NO synthase. 
iNOS protein was not detected in the control or resveratroltreated cells. Since $\mathrm{Ca}^{2+}$-independent eNOS activation occurs by eNOS phosphorylation at $\operatorname{Ser} 1177^{(19,20)}$, the phosphorylation state of the increased eNOS protein was determined. Resveratrol increased phospho-eNOS (peNOS) protein content in a concentration-dependent manner.

To confirm that the increased eNOS protein was functionally active, we determined NO production after HUVEC were exposed to nanomolar concentrations of resveratrol for $5 \mathrm{~d}$ (Fig. 3). NO released into the medium was converted to nitrite, which was then quantified. Resveratrol stimulated NO production in a concentration-dependent manner. In comparison with the control cells, a significant increase in $\mathrm{NO}$ production was observed at $50 \mathrm{~nm}(2 \cdot 2$-fold) and $200 \mathrm{~nm}$ ( $2 \cdot 4$-fold; $P<0 \cdot 05)$. L-NAME potently inhibited NO production in the control and resveratrol-treated cells, indicating that the measured NO was synthesised by NOS $(P<0 \cdot 01$ in control and 200 nM-resveratrol; $P<0.001$ in 10 and 50 nM-resveratrol between vehicle and L-NAME).

In the present study, we further examined the timedependent change in resveratrol-induced eNOS protein expression at $50 \mathrm{~nm}$ (Fig. 4). HUVEC gradually grew and reached confluence on day 5 under our culture condition. Neither cell number nor cell density differed between resveratrol-and vehicle-treated groups during the 5-d period. In fact, cell viability on day 5 was not reduced by resveratrol; $105 \%$ at $50 \mathrm{~nm}$ and $94 \%$ at $200 \mathrm{~nm}$ compared with the control cells. eNOS protein expression was not altered by resveratrol on day 1, whereas the expression was significantly enhanced after exposure to resveratrol for more than $3 \mathrm{~d}$. The increase in eNOS protein content was $2 \cdot 4$-fold on day 3 and $3 \cdot 1$-fold

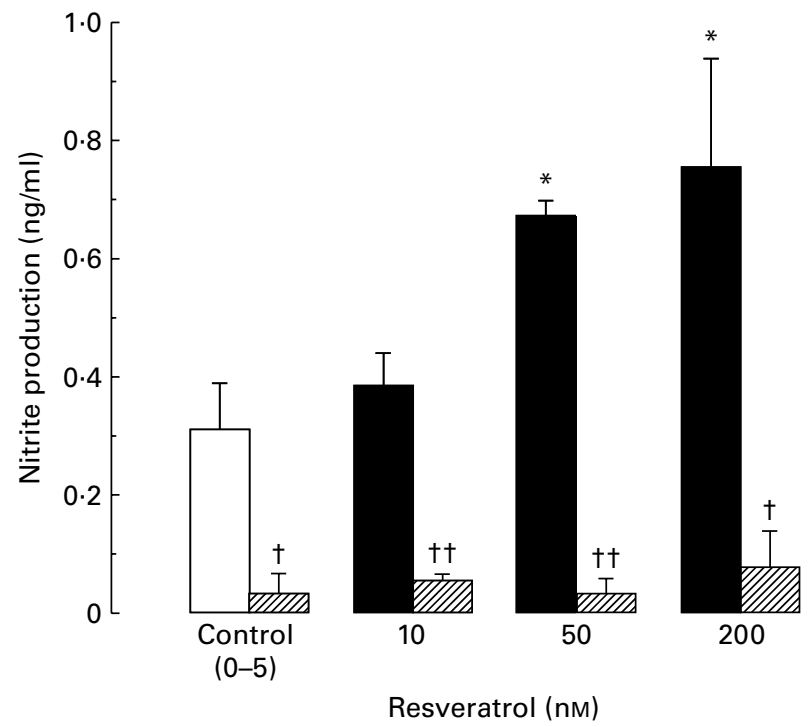

Fig. 3. Concentration-dependent effect of resveratrol on NO production in human umbilical vein endothelial cells (HUVEC). HUVEC were repeatedly treated with vehicle (control) or 10-200 nM-resveratrol for $5 \mathrm{~d}$, and then NO production was determined. Effect of $N^{G}$-nitro-L-arginine methyl ester (L-NAME) is shown by hatched columns. Values are means, with their standard errors represented by vertical bars $(n 8)$. * Mean values were significantly different from those of control without L-NAME $(P<0.01)$. Mean values were significantly different from those of corresponding cells without L-NAME: $\uparrow P<0.01, \dagger \dagger P<0.001$.
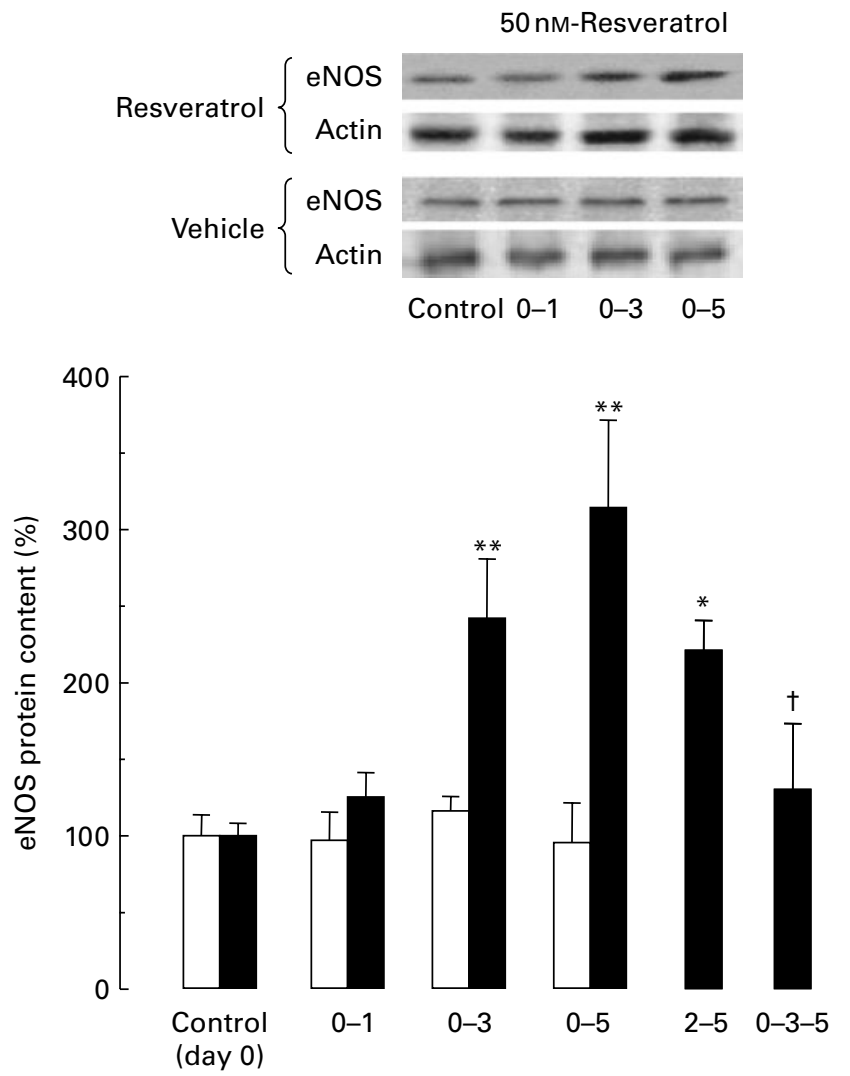

Fig. 4. Time-dependent effect of resveratrol on endothelial NO synthase (eNOS) protein expression in human umbilical vein endothelial cells (HUVEC). HUVEC were repeatedly treated with vehicle ( $\square$ ) or $50 \mathrm{~nm}$-resveratrol $(\square)$ for the indicated periods and then total eNOS protein content was examined by immunoblotting. The ratio of eNOS to $\beta$-actin was determined by densitometry and then expressed as a percentage of the control cells (day 0). Values are means, with their standard errors represented by vertical bars $(n 8)$. Mean values were significantly different from those of control (day $0)$ : ${ }^{\star} P<0.05,{ }^{\star \star} P<0.01$. † Mean values were significantly different from those of resveratrol-treated cells (days $0-3 ; P<0.05$ ). For the schedule of resveratrol treatment, see Fig. 1.

on day 5, compared with that in the cells on day $0(P<0 \cdot 01$ in resveratrol-treated cells between day 0 and day 3 , and between day 0 and day 5). eNOS protein was significantly induced even when the cells were treated with resveratrol from day 2 to day 5 (group 2-5; $P<0.05$ ), indicating that the effect of resveratrol on eNOS protein expression did not depend on cell density or number. In contrast, when the cells were treated with resveratrol for $3 \mathrm{~d}$ followed by depletion for $2 \mathrm{~d}$, eNOS protein content almost returned to the control level (group 0-3-5). eNOS protein expression was not affected by vehicle treatment during the 5 -d period.

Resveratrol-induced eNOS mRNA expression at $50 \mathrm{~nm}$ also increased in a time-dependent manner (Fig. 5). Resveratrol increased eNOS mRNA content by approximately 1.6-fold even on day 1 when eNOS protein expression was not altered. Thereafter, resveratrol significantly increased eNOS mRNA content by $2 \cdot 6$-fold on day $3(P<0.05)$ and $2 \cdot 9$-fold on day 5 $(P<0 \cdot 01)$, compared with that in the cells on day 0. However, resveratrol depletion from day 3 abolished the stimulatory effect on day 5. 


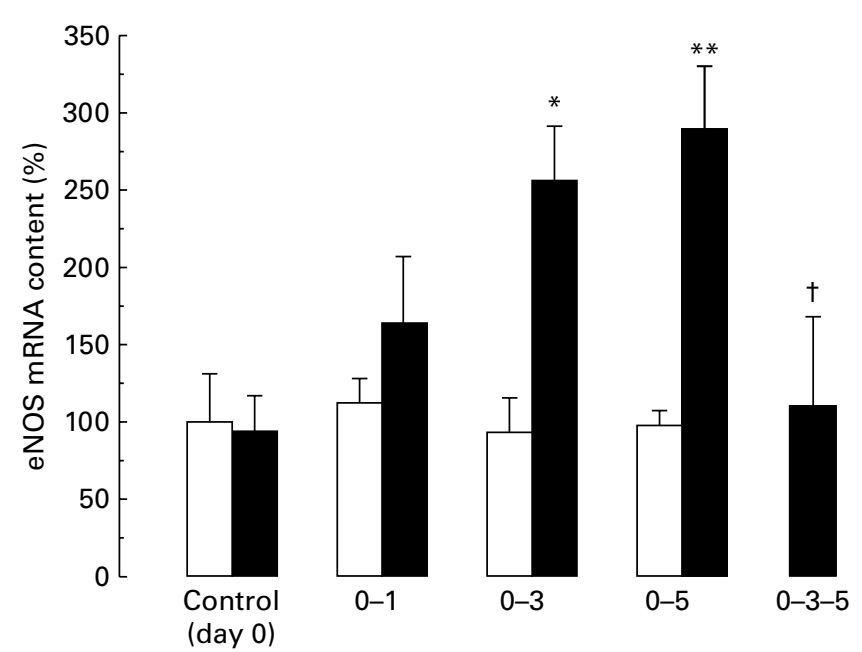

Fig. 5. Time-dependent effect of resveratrol on endothelial NO synthase (eNOS) mRNA expression in human umbilical vein endothelial cells (HUVEC). HUVEC were repeatedly treated with vehicle $(\square)$ or $50 \mathrm{~nm}$-resveratrol ( $\boldsymbol{\square}$ ) for the indicated periods and eNOS mRNA contents were then examined by real-time RT-PCR. The ratio of eNOS to glyceraldehyde 3-phosphate dehydrogenase was determined and then expressed as a percentage of the control cells (day 0 ). Values are means, with their standard errors represented by vertical bars $(n 8)$. Mean values were significantly different from those of control (day 0 ): ${ }^{\star} P<0.05,{ }^{\star \star} P<0.01$. † Mean values were significantly different from those of resveratrol-treated cells (days $0-3 ; P<0.05$ ). For the schedule of resveratrol treatment, see Fig. 1.

The aforementioned results demonstrate that resveratrol upregulates eNOS gene expression, leading to an increase in functional eNOS protein in HUVEC. We further investigated transcriptional regulators involved in the stimulatory effect of resveratrol. It is known that oestrogen receptors $(\mathrm{ER})^{(21,22)}$, PPAR $\alpha^{(23)}$ and $\operatorname{sirtuin}^{(24)}$ are activated by resveratrol. We therefore examined the effects of inhibitors of these molecules on resveratrol-induced eNOS mRNA expression for $3 \mathrm{~d}$ (Fig. 6). The increased eNOS mRNA expression in response to resveratrol was not inhibited by $1 \mu \mathrm{M}-\mathrm{ICI} 182780$ (an ER inhibitor), $50 \mu \mathrm{M}$-Salermide (a sirtuin inhibitor) or $1 \mu \mathrm{M}$-MK886 (a PPAR $\alpha$ inhibitor). However, a combination of ICI182780 and MK886 reduced the increase in resveratrol-induced eNOS mRNA expression. The inhibitors in this combination did not completely reverse this expression, but their inhibitory effect was significant $(P<0.05)$. In contrast, Salermide had no effect even in the presence of ICI182780 or MK886.

\section{Discussion}

In the present study, we have provided evidence that resveratrol within the physiological range acts directly on endothelial cells, resulting in an increase in functional eNOS protein. In animal models, the cardiovascular effects of resveratrol are mediated through $\mathrm{NO}^{(6-10)}$. The stimulatory effect of resveratrol on eNOS protein expression in endothelial cells could contribute to the cardiovascular protection attributed to resveratrol. Nicholson et al. ${ }^{(16)}$ also reported that resveratrol treatment at 1-100 nM for $24 \mathrm{~h}$ caused increased eNOS mRNA content in endothelial cells. They reported that this eNOS
mRNA expression in the resveratrol $(50 \mathrm{~nm})$-treated cells was only 1.6-fold of that in the control cells, consistent with the results of the present study. However, the significance of the slight increase in eNOS mRNA expression remained elusive because Nicholson et al. did not measure eNOS protein content or NO production. The present study showed that eNOS protein content was elevated from day 3, but not day 1 , by resveratrol treatment at $50 \mathrm{~nm}$. In addition, the increased eNOS mRNA and protein contents returned to the control levels within $2 \mathrm{~d}$ of resveratrol depletion from the culture medium. These results indicate that long-term and repeated treatment is required for the physiological effect of resveratrol on eNOS protein expression in endothelial cells. The accumulative effect of nanomolar concentrations of resveratrol might lead to an increase in eNOS protein level.

The amount of peNOS protein was also increased by resveratrol. However, the phosphorylation itself was not affected by resveratrol, as the ratio of peNOS content to total eNOS content was not different between the control and resveratroltreated cells. Akt- and AMP-activated kinases are responsible for eNOS phosphorylation at $\operatorname{Ser} 1177^{(19,20,21)}$. Resveratrol treatment for $5 \mathrm{~d}$ had no effect on the activated state of these protein kinases in HUVEC (data not shown). The increase in peNOS protein might be associated with the increased eNOS protein. These results demonstrate that resveratrol-stimulated $\mathrm{NO}$ production is primarily due to quantitative alteration of total eNOS protein.

Resveratrol increased eNOS protein expression following an increase in eNOS mRNA content in endothelial cells,

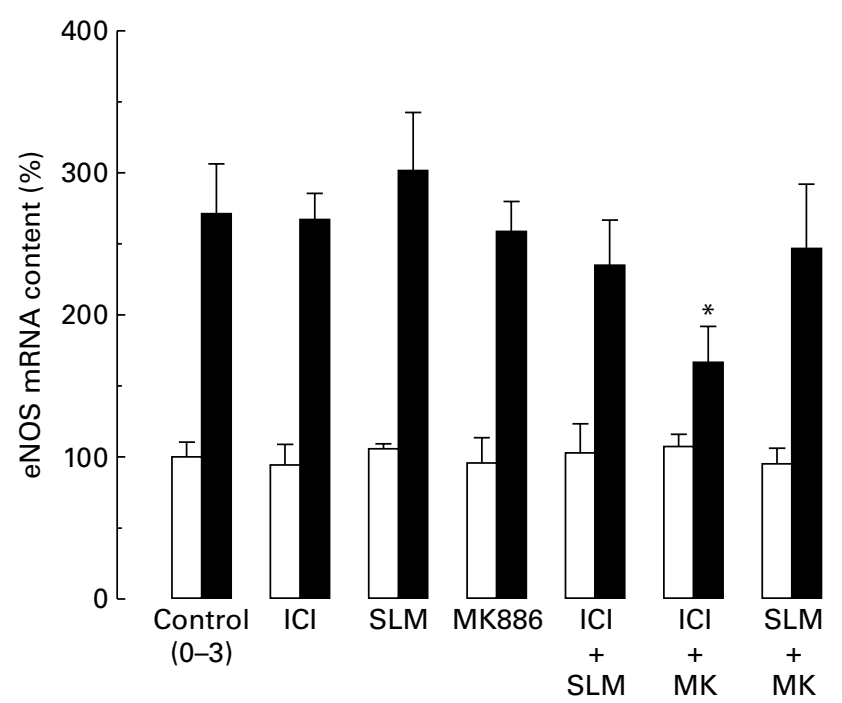

Fig. 6. Effects of ICl182780 (ICl), Salermide (SLM) and MK886 (MK) on resveratrol-induced endothelial NO synthase (eNOS) mRNA expression in human umbilical vein endothelial cells (HUVEC). HUVEC were repeatedly treated with vehicle $(\square)$ or $50 \mathrm{nM}$-resveratrol $(\square)$ for $3 d$ in the presence or absence of the indicated inhibitors, and eNOS mRNA contents were then examined by real-time RT-PCR. The ratio of eNOS to glyceraldehyde 3-phosphate dehydrogenase was determined and expressed as a percentage of the vehicle-treated control cells (days $0-3$ ). Values are means, with their standard errors represented by vertical bars $(n 8)$. * Mean values were significantly different from those of resveratrol-treated control cells (days $0-3 ; P<0.05$ ). For the schedule of resveratrol treatment, see Fig. 1. 
indicating that resveratrol-stimulated induction of eNOS protein implicates eNOS gene expression. Resveratrol has multiple target molecules ${ }^{(25,26)}$, and transcriptional regulators such as ER, sirtuin and PPAR $\alpha$ are among these targets. Combination of ICI182780 and MK886 significantly reduced resveratrol-induced eNOS mRNA expression, although the inhibitors individually had no effect. In contrast, Salermide failed to affect the increased eNOS mRNA expression even in the presence of ICI182780 or MK886. These results suggest that both ER and PPAR $\alpha$, but not sirtuin, might be involved in resveratrol-induced eNOS protein induction. Oestradiol up-regulates eNOS gene expression through ER activation in endothelial cells ${ }^{(27)}$, and resveratrol as a phyto-oestrogen can activate ER in endothelial cells ${ }^{(28)}$. Goya et al. ${ }^{(29)}$ reported that PPAR $\alpha$ agonist fenofibrate elevates eNOS mRNA and protein contents, resulting in an increase in $\mathrm{NO}$ production in endothelial cells. PPAR $\alpha$ in endothelial cells is also activated by resveratrol ${ }^{(23)}$. These previous results are consistent with the present study findings, but resveratrol-stimulated ER or PPAR $\alpha$ alone is unable to up-regulate eNOS mRNA expression. One explanation is that the affinities of resveratrol for ER and PPAR $\alpha$ are lower than those of the potent agonists oestradiol and fibrates. Synergy may exist between the ER and PPAR $\alpha$ pathways for resveratrol-induced eNOS up-regulation. In addition, other mechanisms might lead to resveratrol-induced eNOS expression, because an increase in eNOS mRNA content was observed even when both ER and PPAR $\alpha$ were inhibited.

In addition to eNOS induction, it is also possible that the antioxidant property of resveratrol might be involved in prevention of a decrease in NO bioavailability. Oxidants inhibit eNOS activity by reducing eNOS dimer stability ${ }^{(10,30)}$. Resveratrol is able to stabilise eNOS dimer by scavenging oxidants. Furthermore, resveratrol up-regulates superoxide dismutase and catalase, which inhibit inactivation of NO by the oxygen radicals ${ }^{(10)}$. Overall, resveratrol might exert cardiovascular protection by up-regulating eNOS protein and maintaining NO bioavailability.

We conclude that resveratrol within the physiological range increases eNOS mRNA and protein expression through ER and PPAR $\alpha$ activation, thereby promoting NO production in endothelial cells. eNOS induction might result from the accumulative effect of nanomolar concentrations of resveratrol. The present study results could account in part for the observation that the cardiovascular benefits of red wine are experienced with routine consumption, but not with acute consumption. These findings are helpful in understanding the molecular basis of the beneficial effect of resveratrol.

\section{Acknowledgements}

We thank Tomohiro Shinya (Kyushu University of Health and Welfare) for his assistance. S. T. planned the work, analysed experimental data and wrote the manuscript; S. T. and Y. N. performed the experiments; T. S. helped with the experiments. This research received no specific grant from any funding agency in the public, commercial or not-for-profit sectors. The authors have no conflict of interest to declare.

\section{References}

1. Stoclet J-C, Chataigneau T, Ndiaye M, et al. (2004) Vascular protection by dietary polyphenols. Eur J Pharmacol 500, 299-313.

2. Cordova AC, Jackson LSM, Berke-Schlessel DW, et al. (2005) The cardiovascular protective effect of red wine. $\mathrm{J} \mathrm{Am} \mathrm{Coll}$ Surg 200, 428-439.

3. Opie LH \& Lecour S (2007) The red wine hypothesis: from concepts to protective signalling molecules. Eur Heart J 28, 1683-1693.

4. Sato M, Maulik N \& Das DK (2002) Cardioprotection with alcohol: role of both alcohol and polyphenolic antioxidants. Ann N Y Acad Sci 957, 122-135.

5. Dudzinski DM, Igarashi J, Greif D, et al. (2006) The regulation and pharmacology of endothelial nitric oxide synthase. Ann Rev Pharmacol Toxicol 46, 235-276.

6. Hattori R, Otani H, Maulik N, et al. (2002) Pharmacological preconditioning with resveratrol: role of nitric oxide. $A m J$ Physiol 282, H1988-H1995.

7. Zou JG, Wang ZR, Huang YZ, et al. (2003) Effect of red wine and wine polyphenol resveratrol on endothelial function in hypercholesterolemic rabbits. Int J Mol Med 11, 317-320.

8. Miatello R, Vázquez M, Renna N, et al. (2005) Chronic administration of resveratrol prevents biochemical cardiovascular changes in fructose-fed rats. Am J Hypertens 18, 864-870.

9. Zhang H, Morgan B, Potter B, et al. (2010) Resveratrol improves left ventricular diastolic relaxation in type 2 diabetes by inhibiting oxidative/nitrative stress: in vivo demonstration with magnetic resonance imaging. Am J Physiol 299, H985-H994.

10. Xia N, Daiber A, Habermeier A, et al. (2010) Resveratrol reverses endothelial nitric-oxide synthase uncoupling in apoprotein E knockout mice.J Pharmacol Exp Ther 335, 149-154.

11. Wallerath T, Deckert G, Ternes T, et al. (2002) Resveratrol, a polyphenolic phytoalexin present in red wine, enhances expression and activity of endothelial nitric oxide synthase. Circulation 106, 1652-1658.

12. Goldberg DM, Yan J \& Soleas GJ (2003) Absorption of three wine-related polyphenols in three different matrices by healthy subjects. Clin Biochem 36, 79-87.

13. Walle T, Hsieh F, DeLegge MH, et al. (2004) High absorption but very low bioavailability of oral resveratrol in humans. Drug Metab Dispos 32, 1377-1382.

14. Takahashi S, Uchiyama T \& Toda K (2009) Differential effect of resveratrol on nitric oxide production in endothelial F-2 cells. Biol Pharm Bull 32, 1840-1843.

15. Scifo C, Cardile V, Russo A, et al. (2004) Resveratrol and propolis as necrosis and apoptosis inducers in human prostate carcinoma cells. Oncol Res 14, 415-426.

16. Nicholson SK, Tucker GA \& Brameld JM (2010) Physiological concentrations of dietary polyphenols regulate vascular endothelial cell expression of genes important in cardiovascular health. Br J Nutr 103, 1398-1403.

17. Takahashi S \& Mendelsohn ME (2003) Synergistic activation of endothelial nitric-oxide synthase (eNOS) by HSP90 and Akt. J Biol Chem 278, 30821-30827.

18. Jones R, Baker MB, Weber M, et al. (2009) Molecular beacons can assess changes in expression and $3^{\prime}$-polyadenylation of human eNOS mRNA. Am J Physiol 296, C498-C504.

19. Fulton D, Gratton JP, MaCabe TJ, et al. (1999) Regulation of endothelium-derived nitric oxide production by the protein kinase Akt. Nature 399, 597-601.

20. Dimmeler S, Fleming I, Fisslthaler B, et al. (1999) Activation of nitric oxide synthase in endothelial cells by Aktdependent phosphorylation. Nature 399, 601-605. 
21. Gehm BD, McAndrews JM, Chien PY, et al. (1997) Resveratrol, a polyphenolic compound found in grapes and wine, is an agonist for the estrogen receptor. Proc Natl Acad Sci US A 94, 14138-14143.

22. Bowers JL, Tyulmenkov VV, Jernigan SC, et al. (2000) Resveratrol acts as a mixed agonist/antagonist for estrogen receptors $\alpha$ and $\beta$. Endocrinology $\mathbf{1 4 1}$, 3657-3667.

23. Inoue $\mathrm{H}$, Jiang $\mathrm{XF}$, Katayama $\mathrm{T}$, et al. (2003) Brain protection by resveratrol and fenofibrate against stroke requires peroxisome proliferator-activated receptor $\alpha$ in mice. Neurosci Lett 352, 203-206.

24. Wood JG, Rogina B, Lavu S, et al. (2004) Sirtuin activators mimic caloric restriction and delay ageing in metazoans. Nature 430, 686-689.

25. Jang M, Cai L, Udeani GO, et al. (1997) Cancer chemopreventive activity of resveratrol, a natural product derived from grapes. Science 275, 218-220.
26. Harikumar KB \& Aggarwal BB (2008) Resveratrol: a multitargeted agent for age-associated chronic diseases. Cell Cycle 7, 1020-1035.

27. MacRitchie AN, Jun SS, Chen Z, et al. (1997) Estrogen upregulates endothelial nitric oxide synthase gene expression in fetal pulmonary artery endothelium. Circ Res 81, 355-362.

28. Klinge CM, Blankenship KA, Risinger KE, et al. (2005) Resveratrol and estradiol rapidly activate MAPK signaling through estrogen receptors $\alpha$ and $\beta$ in endothelial cells. J Biol Chem 280, 7460-7468.

29. Goya K, Sumitani S, Xu X, et al. (2004) Peroxisome proliferator-activated receptor $\alpha$ agonists increase nitric oxide synthase expression in vascular endothelial cells. Arterioscler Thromb Vasc Biol 24, 658-663.

30. Xu J, Xie Z, Reece R, et al. (2006) Uncoupling of endothelial nitric oxide synthase by hypochlorous acid: role of $\mathrm{NAD}(\mathrm{P}) \mathrm{H}$ oxidase-derived superoxide and peroxynitrite. Arterioscler Thromb Vasc Biol 26, 2688-2695. 